\title{
Estudo teórico de nanotubos de silício em conformações armchair e zigzag.
}

Pedro Simão S. Mendonça ${ }^{1}(\mathrm{IC})^{*}$, José Divino dos $\operatorname{Santos}^{1}(\mathrm{PQ})$. pedrosimaoqi@gmail.com

${ }^{1}$ UEG Câmpus Henrique Santillo - Rodovia BR-153, 3105 - Fazenda Barreiro do Meio, Anápolis - GO, 75132-400.

Palavras-chave: nanotubos, armchair, zigzag, estudo teórico.

\section{Introdução}

Desde a descoberta de nanotubos de carbono como subproduto de uma síntese de fulereno (IIJIMA, 1991), o interesse foi focado em nanomateriais, especialmente os feitos de carbono, devido suas propriedades de uma física fundamental, bem como o ponto de vista de aplicações possíveis (BAIERLE et al., 2001).

Propriedades eletrônicas semelhantes naturalmente são esperadas para nanoestruturas de alguns outros elementos do grupo IV. Em particular, o silício, uma vez que tem a maior compatibilidade para formação de micro/nano junções com microeletrônica baseada em silício (BAŇACKÝ; NOGA; SZÖCS, 2013).

Aplicando a Teoria do Funcional de Densidade (DFT), Fagan et al. estabeleceu similaridades entre nanotubos de carbono e silício. Seus resultados mostraram que as propriedades eletrônicas e estruturais dos nanotubos de silício (NTSi) são semelhantes as do nanotubo de carbono (NTC), eles podem apresentar comportamento semicondutor ou metálico, dependo do tipo do de sua estrutura (zig zag, armchair ou quiral) e o diâmetro do tubo (FAGAN et al., 2000).

\section{Metodologia}

Com base na ideia de que os nanotubos com hibridização $\mathrm{sp}^{2}$ são estruturas formadas pelo enrolamento de planos tipo grafeno, foram utilizados os dados base de uma estrutura desse tipo, como comprimento de ligação, ângulo de ligação e forma estrutural. As coordenadas espaciais dos nanotubos armchair e zigzag (n,m;n,0) foram obtidas a partir da distribuição dos átomos de silício em uma circunferência de diâmetro "D", chamada de primeiro nível. A obtenção dos demais níveis foi feita pela translação da circunferência no sentido perpendicular ao diâmetro.

As estruturas geradas foram otimizadas utilizando o método PM7. A partir dessas estruturas, foram analisados os nanotubos mais estáveis conforme as configurações armchair e zigzag.

\section{Resultados}

Depois que foram geradas as geometrias dos nanotubos de silício, otimizou-as através de cálculos semi-empírico PM7. Após a otimização obteve-se os valores de energia total da estrutura, gap IHOMO-LUMOI e dipolo para cada conformação. Como pode se observado na Tabela 1. 


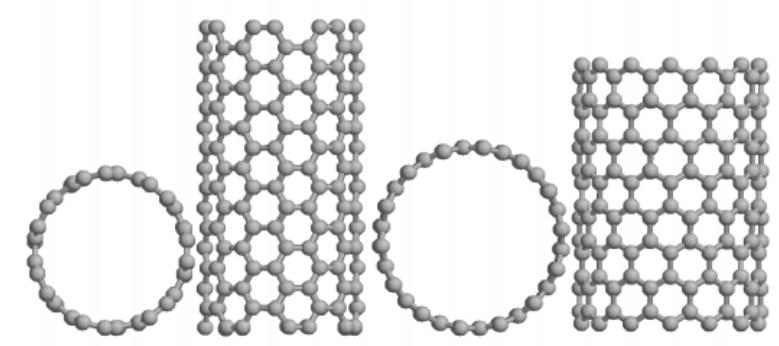

Figura 1: Modelos de nanotubos de nanotubos de silício geradas pelo algoritmo. Respectivamente a estrutura armchair $(n, m)$ e zigzag $(n, 0)$.

Tabela 1: Resultados obtidos através dos cálculos realizados utilizando o método PM7.

\begin{tabular}{|l|c|c|c|c|}
\hline Conformação & Armchair $(5,5)$ & Armchair $(7,7)$ & Zigzag $(5,0)$ & Zigzag $(7,0)$ \\
\hline Energia total (eV) & $-10130,264$ & $-14187,144$ & $-10118,103$ & $-13187,156$ \\
\hline |HOMO-LUMO| & 6,05 & 6,04 & 2,356 & 2,456 \\
\hline Dipolo (debye) & 0,0044 & 0,0103 & 9,701 & 14,506 \\
\hline
\end{tabular}

\section{Discussão}

Os dados da tabela 1 mostram que a estrutura armchair tem uma menor energia que a estrutura zig zag, para um determinado número de átomos, também mostra que para o maior diâmetro e número de átomos, tem-se menor energia dentre as conformações semelhantes. Isso é devido a diminuição da tensão de ligação, diminuindo assim a energia das estruturas. Pelos valores de dipolo e gap IHOMO-LUMOI que as estruturas têm diferentes comportamentos para as distintas conformações, no caso das estruturas com conformações armchair, nota-se comportamento semicondutor e para zigzag comportamento condutor.

\section{Conclusões}

Conclui-se que o comportamento dos nanotubos depende de suas conformações, e que quanto maior o diâmetro da estrutura, menor a tensão da estrutura, diminuindo assim sua energia.

\section{Agradecimentos}

Agradeço ao meu orientador José Divino, meus familiares e a UEG pelos conhecimentos e apoio.

\section{Referências}

IIJIMA, S. Helical microtubules of graphitic carbon. Nature, 354, 56-58, 1991.

FAGAN, S. B.; BAIERLE, R.; MOTA, R.; DA SILVA, A. J. R.; FAZZIO, A. Ab initio calculations for a hypothetical material: Silicon nanotubes. Physical Review B Condensed Matter and Materials Physics, 61, 9994-9996, 2000. 